\title{
Maggots-Friend or Foe? Treating Myiasis in a Patient with Chronic Wounds
}

\author{
James Harrigan, PharmD, Anita Modi, MD, and Gretchen Diemer, MD
}

\section{INTRODUCTION}

Myiasis, or the infestation of living vertebrates with dipterous (two-winged fly) larvae, can take many forms. Depending on their species, maggots will feed on living or dead tissue, liquid body substances, or even ingested food. ${ }^{1}$ The anatomical classification system of such larvae is based on the host location of infestation: sanguinivorous, cavitary, or cutaneous, including furuncular, migratory, or wound. ${ }^{1}$ While pathologic myiasis can result in significant morbidity in both humans and livestock, therapeutic myiasis has played an important role in wound debridement for centuries. This article will explore the varying forms of pathologic cutaneous myiasis and the evolving role of therapeutic myiasis by presenting the case of a patient admitted with newly identified infestation of bilateral lower extremity wounds.



Figure 1. Superficial lower extremity wounds without purulence, edema, erythema, or other evidence of superimposed bacterial infection.

\section{CASE PRESENTATION}

The patient is a 59-year-old homeless man with a history of poorly-controlled schizophrenia who presented to the Thomas Jefferson University Hospital (TJUH) Emergency Department with bilateral leg pain. On examination, his legs had multiple areas of superficial ulceration with pale larvae (Figure 1). There was no purulent drainage to suggest superimposed bacterial infection, and his vital signs and laboratory studies demonstrated no signs of systemic illness. The patient was admitted for management of necrotic wounds complicated by myiasis. Surgery was

\begin{tabular}{|c|c|c|}
\hline Cutaneous Myiasis & \multicolumn{2}{|c|}{ Diptera Larval Species } \\
\hline Furuncle Myiasis & $\begin{array}{l}\text { Dermatobia } \\
\text { Cordylobia } \\
\text { Cuterebra s } \\
\text { Wohlfahrtia } \\
\text { Wopaca }\end{array}$ & $\begin{array}{r}\text { hominis } \\
\text { anthropophagia } \\
p p . \\
\text { vigil }\end{array}$ \\
\hline Migratory Myiasis & $\begin{array}{l}\text { Gasterophilus } \\
\text { Hypoderma spp. }\end{array}$ & intestinalis \\
\hline Wound Myiasis & $\begin{array}{l}\text { Facultative } \\
\text { Lucilia seriata } \\
\text { Obligatory } \\
\text { Cochliomyia } \\
\text { Chrysomya } \\
\text { W magnifica }\end{array}$ & $\begin{array}{r}\text { parasites } \\
\text { parasites } \\
\text { hominivorax } \\
\text { bezziana }\end{array}$ \\
\hline
\end{tabular}

consulted for potential debridement. However, it was noted on inspection that his extremities were devoid of any necrotic tissue to debride. The lack of necrotic tissue was attributed to the maggot infestation. Topical betadine solution was applied and two doses of ivermectin 400 $\mathrm{mcg} / \mathrm{kg} /$ dose were administered to treat concomitant body lice. Three days after initiation of these therapies, the wounds began to exude purulent and malodorous drainage with evidence of newly developed necrotic tissue. Local wound care with daily dressing changes incorporating Santyl (collagenase), Medihoney, and betadine-soaked gauze were continued for the remainder of the hospital course to prevent further infection.

\section{DISCUSSION}

Pathologic myiasis is most frequently seen in tropical and travel medicine settings, though maggots can be easily found all over the world, including the United States. ${ }^{2}$ Cutaneous myiasis-furuncular, migratory, or wound-is the fourth most reported skin disease in returning travelers. ${ }^{3}$ Poor hygiene and low socioeconomic status, which were noted in our patient, serve as risk factors for pathologic myiasis even in developed countries. ${ }^{4}$ Wounds most susceptible to pathologic myiasis include neuropathic ulcers, vascular insufficiency 
ulcers, psoriasis, hemorrhoids, impetigo, and malignant wounds. ${ }^{4}$ Given its prevalence, an understanding of identifying and treating various forms of cutaneous myiasis and superimposed bacterial infections such as tetanus is important.

Furuncular myiasis develops following larval penetration into the healthy exposed skin of travelers or inhabitants of tropical regions, with an incubation period of one to two days. A pruritic, painful, and erythematous nodule forms, with a central dimple facilitating larval respiration and releasing serosanguinous or purulent fluid-and through which a single or multiple larvae can be directly observed. ${ }^{5}$ Agitation and insomnia can occur even in localized myiasis, while systemic symptoms of fevers, chills, and lymphadenopathy suggest secondary bacterial infection.

While larvae responsible for furuncular myiasis tend to stay localized within the primary nodule, those of migratory myiasis burrow through the skin and lead to the development of pruritic lesions with raised red borders. ${ }^{4}$ These erythematous lesions that are the result of initial larval infestation fade to yellow patches once the larva migrates to a new site. In so doing, larvae can live for months in human skin, rarely penetrating visceral organs and brain and lung parenchyma. Migratory myiasis is typically associated with animal exposures, as the Diptera species involved cannot complete their larval life cycles in human hosts and instead relies on cattle and horses as intermediate hosts.

Wound myiasis, such as was seen in our patient, results when flies occupy and lay eggs in open wounds, especially those with necrotic, hemorrhaging, or purulent lesions. ${ }^{4}$ Facultative parasites feed only on dead tissue within a wound, excrete antimicrobial and alkaline substances to inhibit bacterial growth, and stimulate granulationproviding utility in wound debridement for centuries. ${ }^{6}$ Obligatory parasites, on the other hand, require living tissue for larval development, and are thus prone to cause local destruction, fistula formation, as well as invasion of deep tissue requiring immediate removal. ${ }^{5}$ Examination of the wound itself can help determine whether the larvae are facultative or obligatory. Facultative parasites often remain superficial and visible to the naked eye, consuming necrotic tissue on a microscopic level to leave behind clean margins and healthy granulation tissue. Obligatory parasites produce foul-smelling discharge, localized swelling, and deep pockets of infection. Therapeutic myiasis involves the careful selection and sterile harvesting of facultative species, such as Lucilia sericata, which will effectively serve to debride, disinfect, and enhance healing at the wound site (Table 1). Clinical indications for the use of therapeutic myiasis include wounds infected with multi-drug resistant bacteria, superficial wounds, non-healing ulcers and burns, and the presence of significant medical comorbidities precluding surgical debridement. Exudate, wound odor, and pain sores have all been demonstrated to decrease with therapeutic myiasis when compared to conventional dressings. ${ }^{6}$ All studies to date have used laboratory-bred sterile maggots; no studies to our knowledge have evaluated outcomes in patients presenting with wounds already infested with maggots.

Diagnosis of pathologic myiasis is usually clinical, although dermoscopy and ultrasound have been employed in the detection of larvae within furuncular lesions and along migratory tracts. ${ }^{4}$ Peripheral eosinophilia and elevated IgE levels may be observed in patients with chronic or recurrent myiasis, though these values may be normal in the context of acute infestation. Once identified, pathologic larvae should be killed using one of three techniques: application of a toxic substance to the larvae; production of localized hypoxia (i.e. via occlusion of the central dimple with petroleum or paraffin) to force the larvae to emerge from the furuncle; or mechanical/surgical removal of the larvae. ${ }^{4}$ Regardless of the mechanism of killing employed, dead larvae should be removed to prevent secondary bacterial infection. Systemic therapy is not recommended for furuncular myiasis in the absence of secondary bacterial infection, as dead larvae may remain trapped within the nodule, resulting in a subsequent inflammatory reaction and development of a nidus. ${ }^{4}$ Eradication of obligatory parasites in wound myiasis is similarly performed on a local level, involving application of antiseptic solution or topical ivermectin to the wound. In addition, oral ivermectin or albendazole have been reported to bring migratory larvae closer to the skin surface facilitating subsequent extraction.

\section{KEY POINTS}

Therapeutic myiasis has long been employed in controlled settings for the management of chronic, poorly-healing wounds. Enzymes found in the gastrointestinal tracts of some species confer antimicrobial properties to this localized therapy. However, it should be stated that not all maggots are created equal. Obligate larvae feed on all tissues thereby endangering human hosts, while facultative larvae feed preferentially on necrotic tissues-making them ideal therapeutic agents. Despite being used with great regularity for local wound care in ancient cultures, the mere thought of maggots has made many physicians shudder since the advent of germ theory in the second half of the $19^{\text {th }}$ century. ${ }^{6}$ While it has yet to be definitively proven in any scientific studies, preserving and identifying maggots that prefer necrotic over living tissue could help debride extensive wounds and allow for timely healing.

\section{REFERENCES}

1. Sherman RA. Wound Myiasis in Urban and Suburban United States. Archives of Internal Medicine 2000;160:2004-2014

2. Solomon M, Lachish T, Schwartz E. Cutaneous Myiasis. Tropical, Travel, and Emerging Infections 2016:18:28

3. Robbins K, Khachemoune A. Cutaneous Myiasis: A Review of the Common Types of Myiasis. International Journal of Dermatology 2010;49:1092-1098.

4. Francesconi F, Lupi O. Myiasis. Clinical Microbiology Reviews 2012;25:79-105.

5. McGraw TA, Turiansky GW. Cutaneous Myiasis. Journal of the American Academy of Dermatology 2008:58:907-926.

6. Whitaker IS, Twine C, Whitaker MJ, et. al. Larval Therapy from Antiquity to the Present Day: Mechanisms of Action, Clinical Applications, and Future Potential. Postgraduate Medical Journal 2007;83:409-413 